\title{
Nasal Powder Dosage Form
}

National Cancer Institute

\section{Source}

National Cancer Institute. Nasal Powder Dosage Form. NCI Thesaurus. Code C148454.

Solid, usually multidose preparation consisting of one or more powders of solid active substance(s) intended for nasal use by insufflation into the nasal cavity. 